\title{
HPV genotype distribution according to severity of cervical neoplasia using the digene HPV genotyping LQ test
}

\author{
Philippe Halfon - Maria Luisa Mateos Lindemann - Audrey Raimondo • \\ Sophie Ravet · Claire Camus · Hacène Khiri • Guillaume Pénaranda • \\ Mario Sideri • Maria Teresa Sandri
}

Received: 10 August 2012/ Accepted: 17 November 2012/Published online: 9 January 2013

(C) The Author(s) 2013. This article is published with open access at Springerlink.com

\begin{abstract}
A new genotyping-based DNA assay (Digene $\mathrm{LQ}^{\circledR}$ ) was developed recently. The primary aim was to assess the distribution of HPV types using this new assay in atypical squamous cells of undeterminate significance (ASCUS). The secondary aim was to correlate the HPV types with the severity of the disease. The study population comprised 376 ASCUS women. The women were all Hybrid Capture II (HCII) positive and were admitted in three European referral gynecology clinics between 2007 and 2010. A colposcopy with histological examination was performed in all these patients. HPV 16 was typed in $40 \%$ of patients, HPV 18 in $7 \%$, and HPV 31 in $17 \%$, and $18 \%$ of patients had mixed genotypes. Patients aged over 30 more often had the HPV 16 genotype than patients aged under 30 (29\% vs. $11 \%$, chi-square test $p<0.001)$. The risk of cervical intra-epithelial neoplasia of grade 2 or more $(\mathrm{CIN} 2+)$ when HPV 18 positive is lower than the probability associated with HPV 16 or HPV 31: $28 \%$ vs. $58 \%$ and $52 \%$, respectively (chi-square test, $\mathrm{p}=0.005$ and
\end{abstract}

P. Halfon $(\varangle) \cdot$ A. Raimondo - S. Ravet · C. Camus ·

H. Khiri · G. Pénaranda

Laboratoire Alphabio, 23 Rue de Friedland,

13006 Marseille, France

e-mail: philippe.halfon@alphabio.fr

P. Halfon

Unité de Virologie, Hôpital Ambroise Paré,

Marseille, France

M. L. M. Lindemann

Servicio de Microbiología, Hospital Ramón y Cajal,

Madrid, Spain

M. Sideri · M. T. Sandri

Laboratory Medicine Unit, European Institute of Oncology,

Milan, Italy $\mathrm{p}=0.05$, respectively). The Digene $\mathrm{LQ}^{\circledR}$, a new sequencespecific hybrid capture sample preparation, is fast and efficient and allows high-throughput genotyping of $18 \mathrm{HR}$ HPV types by PCR compared to traditional non-sequencespecific sample preparation methods.

\section{Introduction}

High-risk types of human papillomavirus (HPV) are causative agents for cervical cancer. The effectiveness of the cervical screening program could be improved by testing for the DNA of high-risk types of HPV as a primary screening tool [1-3]. More than 200 genotypes have been identified, among which about 40 can infect the mucosa of the anogenital tract. HPV genotypes are classified into "high-risk" HPV (HR HPV), "probable high-risk" HPV, and "low-risk" HPV (LR-HPV) genotypes [3-5]. The classification has been updated, based on epidemiological data. The HR group includes $15 \mathrm{HPV}$ genotypes (types 16, $18,31,33,35,39,45,51,52,56,58,59,68,73,82)$ that proved to be associated with cervical cancer, while the LR group includes $12 \mathrm{HPV}$ genotypes (types 6, 11, 40, 42, 43, $44,54,61,70,72,81$, and CP6108) that are not potentially oncogenic and not involved in the development of cervical cancer [6, 7]. In a recent study, Bouvard et al. [8] suggested that the following 12 genotypes might be HR types: types $16,18,31,33,35,39,45,51,52,56,58$, and 59. Three HPV genotypes (types $26,53,66$ ) are classified as probable HR genotypes because their association with cervical cancer is very difficult to assess, giving a low number of related cases [9]. Some authors have proposed that HPV genotypes $26,53,66,73$, and 82 should be added to the HR genotypes classification associated with cervical cancer $[5,10]$. 
In view of the increasing importance of HPV genotyping, it is important to develop robust, high-throughput assays. Recently, HPV genotyping tests have been presented as relevant for management of screened women, in order to identify which HPV-positive women have persistent oncogenic HPV infection [10,11]. Studies have shown that a single positive test result from either type 16 or type 18 has high predictive value for cervical intra-epithelial neoplasia grade 2 or more (CIN2+) $[4,5,12]$. US guidelines recommend genotyping for type 16 and type 18 in HR HPV-positive women over 30 years of age with normal PAP to determine whether immediate colposcopy is needed [13]. Several genotyping assays have been developed based on different technologies (reverse dot blot, biotinylated MY09/11, DNA-chip technology). These commercial assays allow the detection of 37 HPV genotypes (LA, Roche), 24 HPV genotypes (Papillocheck HPV-screening test, Greiner Bio-One), 35 HPV genotypes (Clinical Arrays, CLART Genomica), and 28 HPV genotypes (INNO-LiPA HPV Genotyping, Innogenetics) [14-17]. The most used genotyping assay, LA, correlates in performance with the HPV Hybrid Capture II (HCII) test for detection of CIN 2+ [18-20].

A novel, commercial system (Digene $\mathrm{LQ}^{\circledR}$ ) for the identification of $18 \mathrm{HR}$ HPV types on GP5+/6+-PCR products was developed and compared analytically to the established Reverse Line Blot (RLB) genotyping assay [21]. Godinez et al. [22] recently performed clinical validation of QIAGEN LQ in women $>40$ years old. However, no clinical validation has been performed in women aged $>18$ years old.

The primary aim of this study was to assess the distribution of HPV types using this new assay. The secondary aim was to correlate the HPV types to the severity of the disease (cytology and histology) with calculation of probabilities of CIN2+ by HPV type.

\section{Materials and methods}

\section{Patients}

The study population comprised 376 atypical squamous cells of undetermined significance (ASCUS) women who were admitted to three European referral gynecology clinics between 2007 and 2010: 158 patients from Madrid (Spain), 123 from Marseille (France), and 95 from Milan (Italy). Criteria for eligibility were age between 18 and 60 years, abnormal cervical smears and HC-II-positive results, and referral for colposcopy with histology. Before colposcopy, a cervical sample was obtained using the ThinPrep method (Cytyc France Sarl, Roissy, France). The cervical scrapes were collected with the PreservCyt transport medium (Cytyc Corp., Marlborough, MA). All of these tests were performed on the samples collected in PreservCyt liquid medium for liquid-based cytology (ThinPrep). Informed consent was obtained from each participant according to the ethics committee guidelines. This study was approved by the CPP Sud-Med I (Comité de Protection des Personnes Sud Méditerranée I) under reference number 0722 .

The following assays were carried out and scored in strict accordance with the manufacturer's instructions.

Hybrid capture II

(HCII) (Digene): this assay detects $13 \mathrm{HR} H P V$ genotypes (HPV16, 18, 31, 33, 35, 39, 45, 51, 52, 56, 58, 59, 68). The HCII test was performed using the automated HCII assay system as described previously (13). For each specimen, results were expressed in relative light unit/cutoff (RLU/ $\mathrm{CO})$, corresponding to the ratio of the specimen luminescence relative to the luminescence of the $1.0 \mathrm{pg} / \mathrm{ml}$ HPV16 standard provided with the kit. Samples with an RLU/CO value $\geq 1$ were considered HCII-HR positive. Samples with an RLU/CO value $<1.0$ were considered HCII-HR negative.

Digene HPV genotyping LQ Test (Digene LQ test) analysis

The Digene LQ test utilizes probes for $18 \mathrm{HR}$ HPV types (i.e., HPV 16,18, 26, 31, 33, 35, 39, 45, 51, 52, 53, 56, 58, $59,66,68,73,82)$ that are the same as the respective RLB probes, with minor modifications, and are immobilized on color-coded beads. The Digene LQ test detection was performed in the Luminex 100 IS System (Luminex Corporation). In brief, 3B buffer was added to the HR HPV beads to minimize the background in the final Luminex read-out. Subsequently, GP5+/6+-PCR products were added. Next, heat-denaturation, hybridization under stringent conditions, and incubation with streptavidin-conjugated R-phycoerythrin detection conjugate were followed by read-out according to the specified instrument settings, resulting in MFI levels per HPV type for each specimen.

Statistical analysis

Two-sided P-values were calculated by Chi-square or Fisher exact tests and placed on $2 \times 2$ contingency tables; Cochran-Armitage test for trend was used for testing trend binomial age proportions across levels of cervical intraepithelial neoplasia. All P-values $<0.05$ were considered statistically significant. Calculations were performed using SAS software (SAS Institute Inc., Cary, NC). 
Table 1 Key characteristics of the 376 ASCUS+ patients

\begin{tabular}{lcccc}
\hline Characteristics & $\begin{array}{l}\text { All ASCUS + patients } \\
(\mathrm{N}=376)\end{array}$ & $\begin{array}{l}\text { Madrid - Spain } \\
(\mathrm{N}=158)\end{array}$ & $\begin{array}{l}\text { Marseille - France } \\
(\mathrm{N}=123)\end{array}$ & $\begin{array}{l}\text { Milan - Italy } \\
(\mathrm{N}=95)\end{array}$ \\
\hline Age; mean $( \pm \mathrm{Sd})$ & $37( \pm 11)$ & $36( \pm 11)$ & $37( \pm 12)$ & $39( \pm 10)$ \\
Smear - N $(\%)$ & & & & \\
ASCUS & $55(15)$ & $8(5)$ & $44(36)$ & $2(2)$ \\
LSIL & $169(45)$ & $87(55)$ & $48(39)$ & $35(37)$ \\
HSIL & $151(40)$ & $63(40)$ & $30(24)$ & $58(61)$ \\
Cancer & $1(-)$ & $0(-)$ & $1(-)$ & $0(-)$ \\
Biopsy - N (\%) & & $11(7)$ & $24(20)$ & $13(14)$ \\
Normal & $48(13)$ & $79(50)$ & $54(44)$ & $28(29)$ \\
CIN1 & $161(43)$ & $41(26)$ & $33(27)$ & $27(28)$ \\
CIN2 & $100(27)$ & $27(17)$ & $11(9)$ & $27(28)$ \\
CIN3 & $65(17)$ & $0(-)$ & $1(-)$ & $0(-)$ \\
Cancer & $2(-)$ & & & $85(89)$ \\
Qiagen HPV LQ - N $(\%)$ & $146(92)$ & $118(96)$ & $10(11)$ \\
Positive (all types) & $349(93)$ & $12(8)$ & $5(4)$ & $95(100)$ \\
Negative & $27(7)$ & $158(100)$ & $123(100)$ & \\
HCII - N (\%) & $376(100)$ & & & \\
Positive (all types) & & & & \\
\hline
\end{tabular}

\section{Results}

Table 1 shows the key characteristics of the 376 ASCUS women. The mean age was 37 ( \pm 11$)$ years (116 were $<30$ years old, and 260 were $\geq 30$ years old); 167 (44\%) were CIN2+, and 67 (18\%) were CIN3+. Digene LQ was found positive in $349(93 \%)$ patients and negative in $27(7 \%)$.

Figure 1 shows the histologic distribution among patients in the age group $<30$ vs. those $\geq 30$ years old. There was no significant correlation between the rate of histologic disease and age group: $25 \%$ (29/116) of $<30$-year-old patients were CIN2, ${ }^{1}$ compared with $27 \%$ (71/260) of $\geq 30$-year-old patients. Similarly, $12 \%$ (14/116) of $<30$-year-old patients were CIN3 compared with $20 \%(51 / 260)$ of $\geq 30$-year-old patients (p-value not significant). The QIAGEN LQ test gave a positive result for 349 patients, and thus, the concordance between Digene LQ and HCII was $93 \%$.

Figure 2 shows the distribution of HPV genotypes using Digene LQ in all patients, in patients aged under 30 years old and in patients aged over 30 years old. Among HPV genotypes, HPV16 was typed in $40 \%$ of patients, HPV 18 in $7 \%$, HPV31 in $17 \%$, and HPV 56 in $7 \%$, and $18 \%$ of patients had mixed genotypes. Among the infections with multiple HPV genotypes $(\mathrm{N}=69), 52(76 \%)$ had two HPV genotypes, 16 (23\%) had three HPV genotypes, and 1 (1\%) had five HPV genotypes. Patients aged over 30

\footnotetext{
${ }^{1}$ Cervical intraepithelial neoplasia (CIN) is graded according to its pathologic progress, from CIN 1 to CIN 3. CIN 2 + stands for CIN 2 and CIN 3 grades.
}

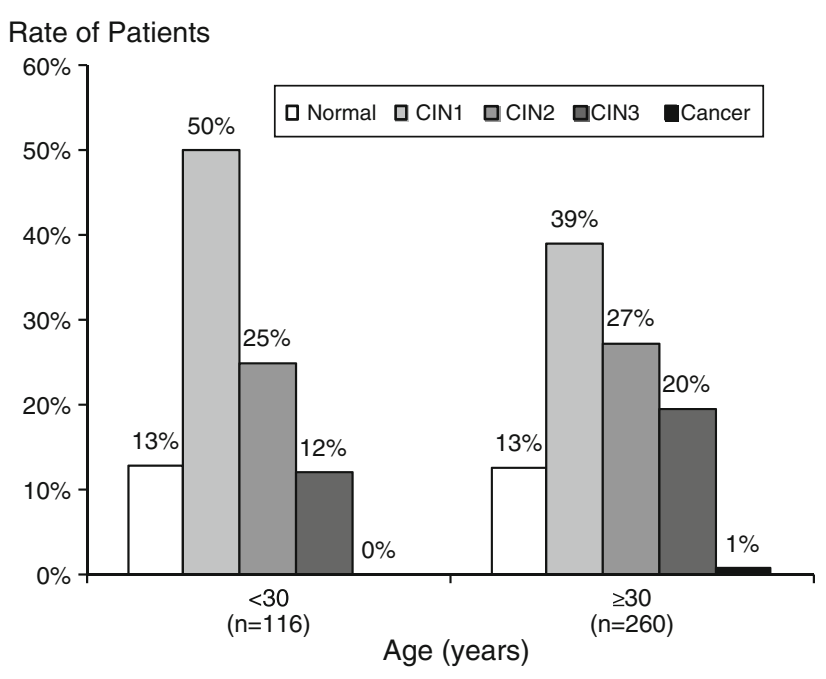

Fig. 1 Histologic distribution among patients in the $<30$ - vs. $\geq 30$ year-old age groups. Bars show the rate of patients with "normal" histology (white bars), "CIN1" histology (light grey bars), or CIN 2, CIN3, or cancer (black bars)) among patients under 30 years old on one side, and over 30 years old on the other side. There was no significant correlation between the rate of histologic disease and age group (Cochran-Armitage test for trend $\mathrm{p}=0.20$ )

more often had the HPV16 genotype than patients aged under 30 (29\% vs. $11 \%$, Chi square test $\mathrm{p}<0.001)$.

Figure 3 shows the risk of CIN2+ according to HPV type. The risk of CIN2+ when HPV 18 is positive is lower than the probability associated with HPV16 or HPV31: $28 \%$ vs. $58 \%$ and $52 \%$, respectively (Chi square test, $\mathrm{p}=0.005$ and $\mathrm{p}=0.05$, respectively). Similarly, the 
Fig. 2 Distribution of HPV genotypes using LQ. Black bars, all 376 patients; white bars, patients aged under 30; grey bars, patients aged over 30 . Patients aged over 30 more often had HPV 16 genotype than patients aged under 30 (29\% vs. $11 \%$, chi-square test $\mathrm{p}<0.001)$

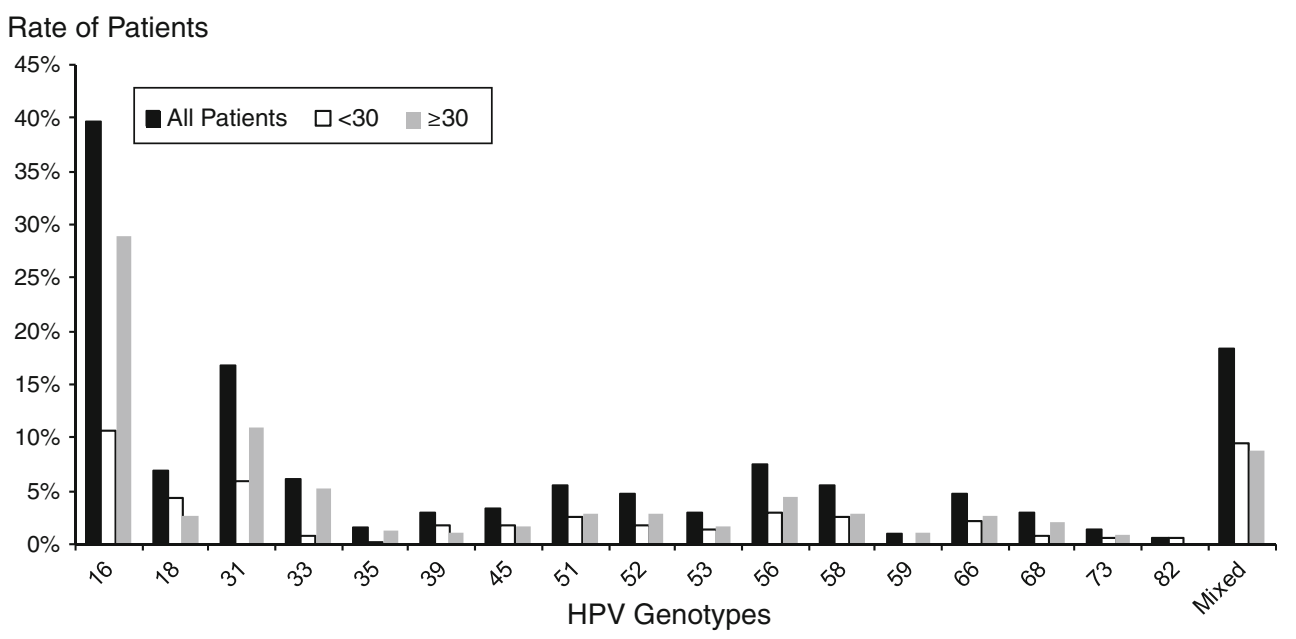

Fig. 3 Risk of CIN2+ according to HPV type. Bars show the rate of patients with the corresponding HPV type among patients with CIN2+ histology. Groups were compared with each other; chi-square test p-values are shown on the line that links the two bars

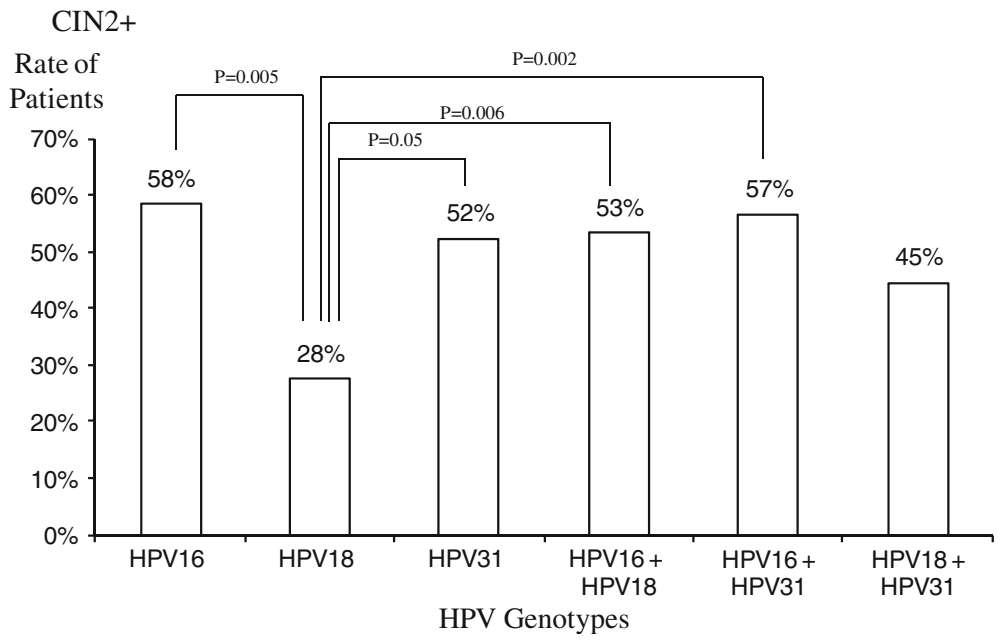

probability of CIN3+ when HPV18 is positive is lower than probability associated with HPV16 but not with HPV31: $3 \%, 23 \%$, and $13 \%$, respectively (Chi square test, $\mathrm{p}=0.026$ and $\mathrm{p}=0.26$, respectively) (Fig. 4).

Figure 5 shows the risk of CIN2+ or CIN3+ according to the combination of HPV genotypes. The risk of CIN2+ when neither HPV16 nor HPV31 is detected is lower than in all other cases (30\%; Chi square, $\mathrm{p}<0.05$ ). Similarly, the risk of CIN2 + when neither HPV16 nor HPV18 is detected is lower than in other cases except HPV18 negative and HPV31 negative (38\% vs. $44 \%$ respectively, Chi square $\mathrm{p}=0.10)$. The risk of CIN3+ when HPV16 is detected, but not HPV18, and the risk of CIN3+ when HPV16 is detected, but not HPV31, are higher than in all other cases, except when neither HPV18 nor HPV31 is detected (24\% and $25 \%$ compared with $20 \%$, respectively).

Table 2 shows the age distribution of HPV genotypes among CIN1 and CIN2+ patients. A significant difference in age distribution was observed in patients with high-risk HPVs (by pooling HPV16, HPV18, HPV31, and other HPV types) $(\mathrm{p}=0.04)$ : an increasing rate of CIN2+ was observed with increasing age (inversely for CIN 1 patients). Similarly, a significant difference in age was observed in patients with "other" HPV types (other than HPV16, HPV18, or HPV31) $(\mathrm{p}=0.04)$.

\section{Discussion}

This multicenter study evaluated for the first time the clinical utility of HPV genotyping using the recently developed Digene $\mathrm{LQ}^{\circledR}$ assay (in atypical squamous cells of undetermined significance, and HCII-positive women referred for colposcopy in three European centers [France, Spain, and Italy]). The distribution of genotypes using this assay indicated, as expected, that HPV types 16, 31/33, 18 and mixed genotypes are the most prevalent, in accordance with previously reported results [23].

The recent ASCCP guidelines recommend the use of HPV genotyping for patient management, with a direct 
Fig. 4 Risk of CIN3+ according to HPV type. Bars show the rate of patients with the corresponding HPV type among patients with CIN3+ histology. Groups were compared with each other; chi-square test $\mathrm{p}$-values are shown on the line that links the two bars
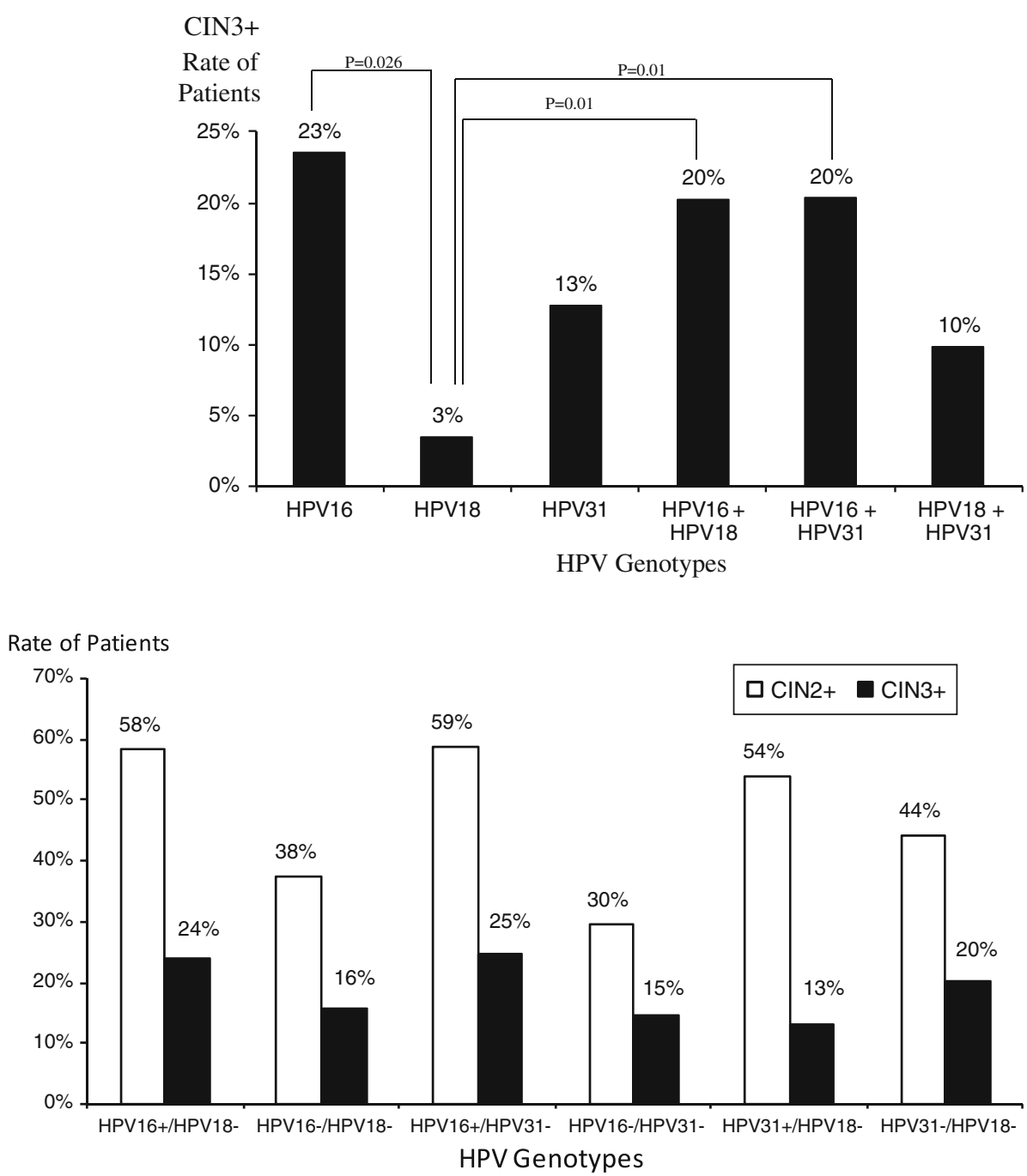

HPV Genotypes
Fig. 5 Risk of CIN2+ and CIN3+ according to HPV type. Bars show the rate of patients with the presence or absence of corresponding HPV types: "+" stands for presence of the HPV type, "-" stands for absence of the HPV type (HPV16+/ HPV18- stands for presence of HPV 16 and absence of HPV 18). White bars are CIN2+ patients, and black bars are CIN3+ patients
Table 2 HPV genotype distribution according to age CIN1 or CIN2+

\begin{tabular}{lrrrr}
\hline & $\begin{array}{l}\text { Age } \\
\text { (years) }\end{array}$ & \multicolumn{1}{l}{ CIN1 } & CIN2+ & P \\
\hline HPV 16/18/31 Positive & $<20$ & $2(67 \%)$ & $1(33 \%)$ & 0.17 \\
& $20-29$ & $25(49 \%)$ & $26(51 \%)$ & \\
& $30-39$ & $29(40 \%)$ & $43(60 \%)$ & \\
& $40-49$ & $16(38 \%)$ & $26(62 \%)$ & \\
$\geq 50$ & $5(36 \%)$ & $9(64 \%)$ & \\
Other HPV & $<20$ & $1(100 \%)$ & $0(-)$ & 0.04 \\
& $20-29$ & $24(71 \%)$ & $10(29 \%)$ & \\
& $30-39$ & $19(73 \%)$ & $7(27 \%)$ & \\
& $40-49$ & $12(46 \%)$ & $14(54 \%)$ & \\
$\geq 50$ & $8(53 \%)$ & $7(47 \%)$ & \\
Overall HPV Positive & $<20$ & $3(75 \%)$ & $1(25 \%)$ & 0.04 \\
& $20-29$ & $49(58 \%)$ & $36(42 \%)$ & \\
& $30-39$ & $48(49 \%)$ & $50(51 \%$ & \\
& $40-49$ & $28(41 \%)$ & $40(59 \%)$ & \\
$\geq 50$ & $13(45 \%)$ & $16(55 \%)$ & \\
\hline
\end{tabular}

referral to colposcopy based on HPV16- and/or HPV18positive results [13]. Moreover, screening with HPV DNA testing for oncogenic genotypes followed by cytological triage has attractive features that may serve the screening needs for a post-vaccination era in the US. However, the methods for HPV typing should be specifically validated with CIN2+ as a clinical endpoint, and comparatively with other methods. This would be a prerequisite for the use of genotyping assays in cervical cancer screening algorithms. Particularly in light of the recent FDA approval of an HPV genotyping test, this study focused on how typing could be used to assist clinical decisions and whether its implementation would be cost-effective [24, 25].

This new sequence-specific Digene LQ test is fast and efficient and allows direct HPV genotyping of 18 HR types by PCR, compared to traditional non-sequence-specific test methods. The utility of this method was evaluated on cervical samples positive for HR HPV by the HCII screening assay from patients referred for colposcopy. 
Among women with ASCUS cytology, the relative probability of pre-cancer is higher in HR HPV-positive women than HR HPV-negative women [20]. Interestingly, using the Digene $\mathrm{LQ}^{\circledR}$, the probability of being CIN2+ when having HPV16 is $58 \%$, similar to the probability associated with HPV $31,52 \%$, and the probability is $28 \%$ if HPV18 positive. The probability of being CIN3+ when having HPV16 is $23 \%$ (the probability is $3 \%$ if HPV18 positive, and $13 \%$ if HPV31 positive). The relative probability of CIN2+ when being HPV16+/HPV18- is $58 \%$ (the probability of CIN $3+$ is $24 \%$ ). Similarly, the probability of CIN2+ when being HPV16+/HPV31 is $59 \%$ (the probability of CIN3+ is $25 \%$ ), and the probability of CIN2+ when being HPV31+/HPV18- is $54 \%$ (the probability of CIN3+ is $13 \%$ ).

These data are similar to those reported in the recently published ATHENA study: HPV16/HPV18+ women had a greater probability of CIN 2 or worse compared with pooled HR-HPV + and HR-HPV- women (24.4\%, $14.0 \%$, and $0.8 \%$, respectively) [20].

Among HR-HPV-positive women, risk of disease likely increases over time, as has been reported for genotypes 16 and 18 by Khan et al. [12]. Up to now, the risk threshold for performing colposcopy in response to specific cytology and HPV test results has not been defined. Castle et al. suggested that women with a probability for CIN $3+$ disease of $10 \%$ or greater over two years should be investigated [26].

While all women with ASCUS cytology testing positive for HR HPV should be referred for colposcopy, the results from this study demonstrate that those women with ASCUS cytology testing positive with HPV16 and/or 18 and 31 are at a particularly high risk for $\geq$ CIN3 disease, reinforcing the need for immediate colposcopy and more intense follow-up, particularly in the case of a negative colposcopy. These findings corroborate those of other studies [27, 28].

This study points out the greater probability of CIN2 and CIN3 for patients testing positive for HPV31. HPV31 is a more prevalent type than HPV18 in the ASCUS population in European countries [19, 29]. Notably, this study highlights that the probability of HPV31 is greater than that of HPV18. This was also observed by Söderlund et al. [30]: an odds ratio of the risk of CIN2+ or CIN3+ was 3.79 and 2.83 for HPV31 vs. 1.46 and 0.82 for HPV18, respectively.

Another prevalent genotype in our population was HPV56, found in the same proportion as HPV18.

Regarding the laboratory technical characteristics, this assay uses multiplex, bead-based XMAP technology and an automated, high-throughput read-out by either the LiquiChip 200 workstation (QIAGEN, Hilden, Germany) or Luminex 100 IS System (Luminex Corporation, Austin,
TX). The test was developed for identification of the $18 \mathrm{HR}$ HPV genotypes associated with cervical cancer using GP5+/6+-PCR products. The Digene LQ Test and the RLB assay have been reported to have a high level of agreement in detection and genotyping of 18 HR HPV types in HCII-positive specimens [21].

\section{Conclusions}

The Digene $\mathrm{LQ}^{\circledR}$, a new sequence-specific HC sample preparation is fast and efficient and allows high-throughput genotyping of $18 \mathrm{HR}$ HPV types by PCR compared to traditional non-sequence-specific sample preparation methods. This study showed that HPV types $16,31,33,18$ and mixed genotypes are the most prevalent genotypes and that ASCUS women who are HPV16 positive have the highest probability of CIN2+ and CIN3+.

Acknowledgments We thank the QIAGEN team for kindly providing the reagents of the study.

Competing interests The authors declare that they do not have any conflict of interest.

Authors' contributions PH conceived the study and drafted the manuscript. MLML, MS, MTS participated in the design of the study and in drafting the manuscript. AR, SR, HK carried out genotyping analyses. GP performed the statistical analysis and participated in drafting the manuscript.

Open Access This article is distributed under the terms of the Creative Commons Attribution License which permits any use, distribution, and reproduction in any medium, provided the original author(s) and the source are credited.

\section{References}

1. Sherman ME, Lorincz AT, Scott DR, Wacholder S, Castle PE, Glass AG, Mielzynska-Lohnas I, Rush BB, Schiffman M (2003) Baseline cytology, human papillomavirus testing, and risk for cervical neoplasia: a 10-year cohort analysis. J Natl Cancer Inst 95(1):46-52

2. Cuzick J, Arbyn M, Sankaranarayanan R, Tsu V, Ronco G, Mayrand MH, Dillner J, Meijer CJ (2008) Overview of human papillomavirus-based and other novel options for cervical cancer screening in developed and developing countries. Vaccine 26(Suppl 10):K29-K41

3. Munoz N, Bosch FX, de Sanjose S, Herrero R, Castellsague X, Shah KV, Snijders PJ, Meijer CJ (2003) Epidemiologic classification of human papillomavirus types associated with cervical cancer. N Engl J Med 348(6):518-527

4. Woodman CB, Collins SI, Young LS (2007) The natural history of cervical HPV infection: unresolved issues. Nat Rev Cancer $7(1): 11-22$

5. zur Hausen H (2002) Papillomaviruses and cancer: from basic studies to clinical application. Nat Rev Cancer 2(5):342-350 
6. Meijer CJ, Snijders PJ, Castle PE (2006) Clinical utility of HPV genotyping. Gynecol Oncol 103(1):12-17

7. Smith JS, Lindsay L, Hoots B, Keys J, Franceschi S, Winer R, Clifford GM (2007) Human papillomavirus type distribution in invasive cervical cancer and high-grade cervical lesions: a metaanalysis update. Int J Cancer 121(3):621-632

8. Bouvard V, Baan R, Straif K, Grosse Y, Secretan B, El Ghissassi F, Benbrahim-Tallaa L, Guha N, Freeman C, Galichet L, Cogliano V (2009) A review of human carcinogens-part B: biological agents. Lancet Oncol 10(4):321-322

9. Munoz N, Castellsague X, de Gonzalez AB, Gissmann L (2006) Chapter 1: HPV in the etiology of human cancer. Vaccine 24 (Suppl 3):S3/1-10

10. Snijders PJ, van den Brule AJ, Meijer CJ (2003) The clinical relevance of human papillomavirus testing: relationship between analytical and clinical sensitivity. J Pathol 201(1):1-6

11. Arbyn M, Ronco G, Cuzick J, Wentzensen N, Castle PE (2009) How to evaluate emerging technologies in cervical cancer screening? Int J Cancer 125:2489-2496

12. Khan MJ, Castle PE, Lorincz AT, Wacholder S, Sherman M, Scott DR, Rush BB, Glass AG, Schiffman M (2005) The elevated 10 -year risk of cervical precancer and cancer in women with human papillomavirus (HPV) type 16 or 18 and the possible utility of type-specific HPV testing in clinical practice. J Natl Cancer Inst 97(14):1072-1079

13. Wright TC Jr, Massad LS, Dunton CJ, Spitzer M, Wilkinson EJ, Solomon D (2007) 2006 consensus guidelines for the management of women with abnormal cervical cancer screening tests. Am J Obstet Gynecol 197(4):346-355

14. Else EA, Swoyer R, Zhang Y, Taddeo FJ, Bryan JT, Lawson J, Van Hyfte I, Roberts CC (2011) Comparison of real-time multiplex human papillomavirus (HPV) PCR assays with INNOLiPA HPV genotyping extra assay. J Clin Microbiol 49: 1907-1912

15. Szarewski A, Ambroisine L, Cadman L, Austin J, Ho L, Terry G, Liddle S, Dina R, McCarthy J, Buckley H, Bergeron C, Soutter P, Lyons D, Cuzick J (2008) Comparison of predictors for highgrade cervical intraepithelial neoplasia in women with abnormal smears. Cancer Epidemiol Biomarkers Prev 17(11):3033-3042

16. Halfon P, Benmoura D, Agostini A, Khiri H, Penaranda G, Martineau A, Blanc B (2010) Stepwise algorithm combining HPV high-risk DNA-based assays and RNA-based assay for high grade CIN in women with abnormal smears referred to colposcopy. Cancer Biomark 7(3):133-139

17. Poljak M, Kocjan BJ (2010) Commercially available assays for multiplex detection of alpha human papillomaviruses. Expert Rev Anti Infect Ther 8(10):1139-1162. doi:10.1586/eri.10.104

18. Monsonego J, Pollini G, Evrard MJ, Sednaoui P, Monfort L, Zerat L, Syrjanen K (2008) Detection of human papillomavirus genotypes among high-risk women: a comparison of hybrid capture and linear array tests. Sex Transm Dis 35(5):521-527

19. Halfon P, Benmoura D, Khiri H, Penaranda G, Blanc B, Riggio D, Sandri MT (2010) Comparison of the clinical performance of carcinogenic HPV typing of the linear array and Papillocheck HPV-screening assay. J Clin Virol 47(1):38-42

20. Stoler MH, Wright TC Jr, Sharma A, Apple R, Gutekunst K, Wright TL (2011) High-risk human papillomavirus testing in women with ASC-US cytology: results from the ATHENA HPV Study. Am J Clin Pathol 135(3):468-475
21. Geraets DT, Heideman DA, de Koning MN, Snijders PJ, van Alewijk DC, Meijer CJ, van Doorn LJ, Quint WG (2009) Highthroughput genotyping of high-risk HPV by the digene HPV genotyping LQ test using GP5+/6+-PCR and xMAP technology. J Clin Virol 46(Suppl 3):S21-S26

22. Godinez JM, Tous S, Baixeras N, Moreno-Crespi J, Alejo M, Lejeune M, Bravo IG, Bosch FX, de Sanjose S (2011) Performance of the digene LQ, RH and PS HPVs genotyping systems on clinical samples and comparison with $\mathrm{HC} 2$ and PCR-based linear array. Infect Agent Cancer 6:23. doi:10.1186/17509378-6-23

23. de Sanjose S, Diaz M, Castellsague X, Clifford G, Bruni L, Munoz N, Bosch FX (2007) Worldwide prevalence and genotype distribution of cervical human papillomavirus DNA in women with normal cytology: a meta-analysis. Lancet Infect Dis 7(7):453-459. doi:10.1016/S1473-3099(07)70158-5

24. Saslow D, Solomon D, Lawson HW, Killackey M, Kulasingam SL, Cain J, Garcia FA, Moriarty AT, Waxman AG, Wilbur DC, Wentzensen N, Downs LS Jr, Spitzer M, Moscicki AB, Franco EL, Stoler MH, Schiffman M, Castle PE, Myers ER (2012) American Cancer Society, American Society for Colposcopy and Cervical Pathology, and American Society for Clinical Pathology screening guidelines for the prevention and early detection of cervical cancer. CA Cancer J Clin 62(3):147-172. doi: 10.3322/caac. 21139

25. Saslow D, Solomon D, Lawson HW, Killackey M, Kulasingam SL, Cain JM, Garcia FA, Moriarty AT, Waxman AG, Wilbur DC, Wentzensen N, Downs LS Jr, Spitzer M, Moscicki AB, Franco EL, Stoler MH, Schiffman M, Castle PE, Myers ER (2012) American Cancer Society, American Society for Colposcopy and Cervical Pathology, and American Society for clinical Pathology Screening Guidelines for the Prevention and Early Detection of Cervical Cancer. J Low Genit Tract Dis 16(3):175-204. doi: 10.1097/LGT.0b013e31824ca9d5

26. Castle PE, Sideri M, Jeronimo J, Solomon D, Schiffman M (2007) Risk assessment to guide the prevention of cervical cancer. Am J Obstet Gynecol 197(4):356 e351-356

27. Castle PE, Stoler MH, Wright TC Jr, Sharma A, Wright TL, Behrens CM (2011) Performance of carcinogenic human papillomavirus (HPV) testing and HPV16 or HPV18 genotyping for cervical cancer screening of women aged 25 years and older: a subanalysis of the ATHENA study. Lancet Oncol 12(9):880-890. doi:10.1016/S1470-2045(11)70188-7

28. Sundstrom K, Eloranta S, Sparen P, Arnheim Dahlstrom L, Gunnell A, Lindgren A, Palmgren J, Ploner A, Sanjeevi CB, Melbye M, Dillner J, Adami HO, Ylitalo N (2010) Prospective study of human papillomavirus (HPV) types, HPV persistence, and risk of squamous cell carcinoma of the cervix. Cancer Epidemiol Biomarkers Prev 19(10):2469-2478. doi:10.1158/10559965.EPI-10-0424

29. Halfon P, Benmoura D, Agostini A, Khiri H, Martineau A, Penaranda G, Blanc B (2010) Relevance of HPV mRNA detection in a population of ASCUS plus women using the NucliSENS EasyQ((R)) HPV assay. J Clin Virol 47:177-181

30. Soderlund-Strand A, Eklund C, Kemetli L, Grillner L, Tornberg S, Dillner J, Dillner L (2011) Genotyping of human papillomavirus in triaging of low-grade cervical cytology. Am J Obstet Gynecol. doi:10.1016/j.ajog.2011.03.056 